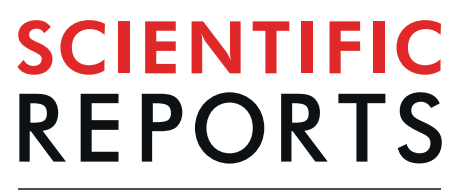

natureresearch

Check for updates

\title{
OPEN A facile approach to hydrophilic oxidized fullerenes and their derivatives as cytotoxic agents and supports for nanobiocatalytic systems
}

\author{
Panagiota Zygouri $\oplus^{1,2} \llbracket$, Konstantinos Spyrou ${ }^{1,2}$, Efstratia Mitsari ${ }^{3}$, María Barrio ${ }^{3}$, \\ Roberto Macovez ${ }^{3}$, Michaela Patila ${ }^{4}$, Haralambos Stamatis ${ }^{4}$, loannis I. Verginadis ${ }^{5,7}$, \\ Anastasia P. Velalopoulou ${ }^{5,7}$, Angelos M. Evangelou ${ }^{5}$, Zili Sideratou ${ }^{6}$, Dimitrios Gournis ${ }^{1 凶}$ \& \\ Petra Rudolf $\mathbb{C}^{2 \otimes}$
}

\begin{abstract}
A facile, environment-friendly, versatile and reproducible approach to the successful oxidation of fullerenes $\left(\mathrm{oxC}_{60}\right)$ and the formation of highly hydrophilic fullerene derivatives is introduced. This synthesis relies on the widely known Staudenmaier's method for the oxidation of graphite, to produce both epoxy and hydroxy groups on the surface of fullerenes $\left(C_{60}\right)$ and thereby improve the solubility of the fullerene in polar solvents (e.g. water). The presence of epoxy groups allows for further functionalization via nucleophilic substitution reactions to generate new fullerene derivatives, which can potentially lead to a wealth of applications in the areas of medicine, biology, and composite materials. In order to justify the potential of oxidized $\mathrm{C}_{60}$ derivatives for bio-applications, we investigated their cytotoxicity in vitro as well as their utilization as support in biocatalysis applications, taking the immobilization of laccase for the decolorization of synthetic industrial dyes as a trial case.
\end{abstract}

The discovery ${ }^{1}$ of fullerene $\left(\mathrm{C}_{60}\right)$ in 1985 and the establishment of a protocol for its bulk production ${ }^{2}$ has had a widespread impact throughout science due to $\mathrm{C}_{60}$ 's special physico-chemical and optical properties, as well as the specific chemical reactivity resulting from the unique cage structure ${ }^{3}$. Fullerene research has produced breakthrough highlights in the fields of superconductivity, organic ferromagnets, photovoltaics, thin-film transistors, and catalysis ${ }^{4-13}$. Nonetheless, the exploitation of this extraordinary molecule for applications in disciplines such as biochemistry, biology and medicine is hampered by its insolubility in a large number of solvents including especially water, where aggregation of the $\mathrm{C}_{60}$ molecules into micelle-like clusters is observed ${ }^{14}$. This problem has been addressed with the help of functionalization chemistry ${ }^{15,16}$, leading to water-soluble fullerene hybrids ${ }^{17,18}$ and to the synthesis of numerous fullerenes derivatives ${ }^{19,20}$ targeted to meet specific needs in materials science ${ }^{21}$, biomedical chemistry ${ }^{18,22-24}$, and pharmaceutical research ${ }^{25}$.

Over the last decades covalent functionalization of fullerenes has been extended to include various functionalization reactions $s^{3,19,25-27}$, among which the most commonly employed is the Prato reaction for fullerene functionalization through fulleropyrrolidine formation based on the 1,3 dipolar cycloaddition ${ }^{28-30}$. As a result, a

\footnotetext{
${ }^{1}$ Department of Materials Science and Engineering, University of loannina, GR-45110, loannina, Greece. ${ }^{2}$ Zernike Institute for Advanced Materials, University of Groningen, Nijenborgh 4, NL-9747AG, Groningen, the Netherlands. ${ }^{3}$ Grup de Caracterització de Materials, Departament de Física and Barcelona Research Center in Multiscale Science and Engineering, Universitat Politècnica de Catalunya, EEBE, Campus Diagonal-Besòs, Av. Eduard Maristany 1014, 08019, Barcelona, Spain. ${ }^{2}$ Department of Biological Applications and Technologies, University of loannina, GR45110, loannina, Greece. ${ }^{5}$ Laboratory of Physiology, School of Medicine, Faculty of Health Sciences, University of loannina, GR-45110, loannina, Greece. 'Institute of Nanoscience and Nanotechnology, NCSR "Demokritos", 15310, Aghia Paraskevi, Attikis, Greece. ${ }^{7}$ Present address: Department of Radiation Oncology, The Perelman School of Medicine, University of Pennsylvania, 3400 Civic Boulevard, Philadelphia, PA, 19104, USA. ${ }^{\circledR}$ e-mail: pzygouri@ gmail.com; dgourni@uoi.gr; p.rudolf@rug.nl
} 


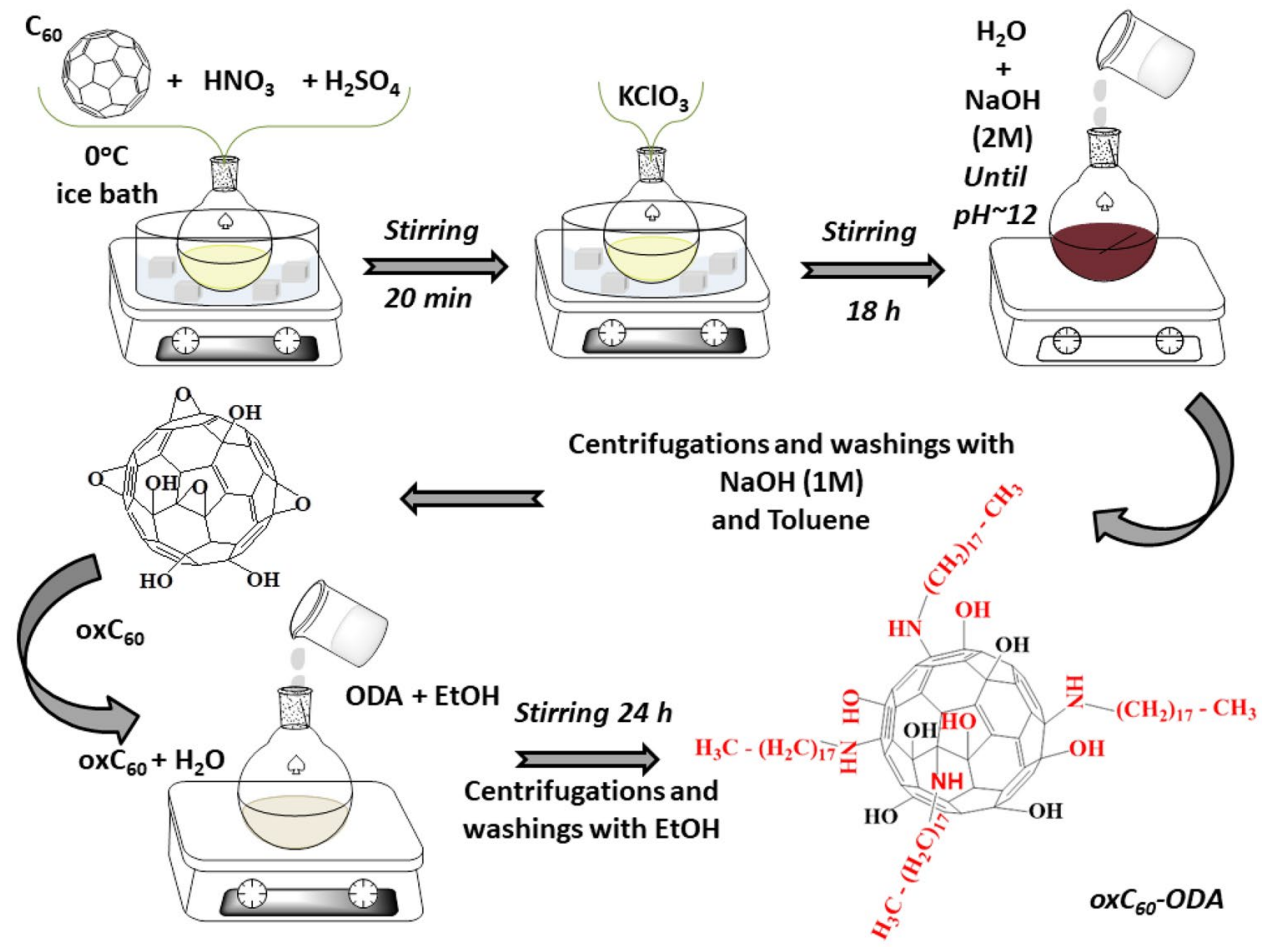

Figure 1. Synthetic method for the production of oxidized $\mathrm{C}_{60}$ and its derivatives.

plethora of organic reagents rich in biological and pharmaceutical activity have been covalently attached to $\mathrm{C}_{60}$, yielding derivatives with enhanced properties for a broad range of biological and medicinal applications ${ }^{18,23,31-36}$. All these reactions imply complicated manipulation and require special experience in handling. There is therefore a growing demand for controllable and easy-to-handle methods for the functionalization of $\mathrm{C}_{60}$.

Here we report a novel, easy, versatile, and reproducible procedure for the chemical oxidation of $\mathrm{C}_{60}$, on the basis of Staudenmaier's method ${ }^{37}$, which is a controllable synthesis, extensively studied for the oxidation of graphite into graphene oxide ${ }^{38}$. We wish to emphasize that we used a variant of Staudenmaier's method here because fullerenes are more sensitive than other carbon forms (CNTs, Graphene) and hence direct application of Staudenmaier's method may lead to insufficient and not well-defined structures and functional groups. We show that through a variant of this method, the properties of pristine fullerenes can be tailored, introducing a combination of oxygenated functional groups, which in turn constitute reacting sites for chemical derivatization. In comparison with the other oxidation methods ${ }^{39-49}$ our proposed procedure exhibits a higher yield of oxygen functional groups and therefore greatly enhances the fullerene's hydrophilicity, while the epoxy groups provide the ability to interact covalently with amines at ambient conditions. Contrary to other protocols reported in the literature, this synthesis method does not require high temperature $\mathrm{s}^{50}$ nor does it lead to the creation of clusters, aggregation or by-products ${ }^{51}$, all phenomena hindering hydrophilicity ${ }^{52}$. Our approach is suitable for up-scaling to mass production because, differently from other methods reported, because it presents no inherent synthetic difficulties and/or yield limitations $s^{51,53,54}$. In more detail, as a consequence of the strong acid treatment, the surface of the fullerene molecule is decorated with diverse oxygen functionalities, converting the completely insoluble fullerene into a hydrophilic molecule soluble in many polar solvents, while maintaining its stereochemistry (spherical shape). To substantiate this claim, we have investigated the evaluation of the in vitro cytotoxic activity of the $\mathrm{C}_{60}$ hybrids, performed against mouse leiomyosarcoma (LMS) and human lung cancer (A549), as well as a normal cell line, normal human fetal lung fibroblasts (MRC-5).

An additional huge benefit derived from the creation of epoxy moieties is the possibility of further functionalization with numerous organic species via covalent bonding to the epoxy groups, a method that has been extensively employed for the chemical functionalization of graphite oxide $\mathrm{e}^{55-57}$. Further functionalization of oxidized $\mathrm{C}_{60}$ with a primary aliphatic amine was performed to confirm the presence of epoxy moieties and to attest this oxidative method as a controllable and reproducible step for the creation of new $\mathrm{C}_{60}$ derivatives. X-ray photoelectron (XPS), Raman and Fourier transform infrared (FTIR) spectroscopies, differential scanning calorimetry (DSC) and thermogravimetric analysis (TGA), in conjunction with powder X-ray diffraction (XRD) measurements were performed for the material's characterization.

The following figure (Fig. 1) illustrates the synthetic method for the production of oxidized $\mathrm{C}_{60}$ and its derivatives.

Laccases (benzenediol: oxygen oxidoreductase; E.C. 1.10.3.2) belong to multi-copper containing oxidases and their activity is based on the reduction of molecular oxygen to water with the simultaneous one-electron oxidation of aromatic substrates ${ }^{58}$. In addition, laccases, due to their ability to oxidize different substrates, are potential candidates for many biotechnological and industrial applications, such as decolorization of synthetic dyes ${ }^{59}$. 
Herein, the immobilization of a native laccase from White rot fungi on the newly synthesized oxC ${ }_{60}$-ODA was performed and further used for the decolorization of two synthetic dyes with industrial applications.

\section{Material and methods}

Production of oxidized fullerene $\left(\mathrm{oxC}_{60}\right)$. $\quad \mathrm{oxC}_{60}$ was obtained by a modified Staudenmaier's method. In a conical flask, $100 \mathrm{mg}$ of $\mathrm{C}_{60}\left(98 \%\right.$, Sigma-Aldrich) were added upon stirring to a mixture of $4 \mathrm{~mL}$ of $\mathrm{H}_{2} \mathrm{SO}_{4}$ (95-97\%) and $2 \mathrm{~mL}$ of $\mathrm{HNO}_{3}(65 \%)$ kept in an ice-water bath at $0{ }^{\circ} \mathrm{C} .700 \mathrm{mg}$ of $\mathrm{KClO}_{3}$ were then added in little portions to the solution under vigorous stirring and the reaction was continued for 18 hours. $20 \mathrm{~mL}$ water were then added and the mixture was stirred for another 30 minutes. The resulting aqueous acid mixture was neutralized by slowly adding a $2 \mathrm{M} \mathrm{NaOH}$ solution until a $\mathrm{pH}$ of 12 was reached. The precipitate was separated from the solution by centrifugation, washed with a $1 \mathrm{M} \mathrm{NaOH}$ solution and centrifuged again ${ }^{60}$. The product was washed three times in order to eliminate the remaining salts used or formed during the oxidation procedure. The precipitate was dispersed in $50 \mathrm{~mL}$ of toluene, stirred for $20 \mathrm{~min}$ and centrifuged to remove unreacted fullerenes. Finally, the oxidation product was dispersed in ethanol and air-dried on a glass plate. The final material possessed a yield of approximately $50 \%$ (based on the weighted mass).

Characterization tools. Fourier transform infrared (FT-IR) spectra over the spectra range $400-4000 \mathrm{~cm}^{-1}$ were recorded with a Perkin-Elmer Spectrum GX infrared spectrometer featuring a deuterated triglycine sulphate (DTGS) detector. Every spectrum was the average of 64 scans taken with $2 \mathrm{~cm}^{-1}$ resolution. Samples were prepared as $\mathrm{KBr}$ pellets with ca. $2 \mathrm{wt} \%$ of sample. Raman spectra were collected with a Micro - Raman system RM 1000 RENISHAW, using a laser excitation line at $532 \mathrm{~nm}(\mathrm{Nd}-\mathrm{YAG})$, in the range of $1000-2400 \mathrm{~cm}^{-1}$. A power of $1 \mathrm{~mW}$ was utilized with a $1 \mu \mathrm{m}$ focusing spot so to avoid photodecomposition of the samples. ${ }^{13} \mathrm{C}$ NMR spectrum of oxC $_{60}$ was recorded in $\mathrm{D}_{2} \mathrm{O}$ using a Bruker Avance DRX spectrometer operating at $125.1 \mathrm{MHz}$. Thermogravimetric measurements were carried out with a Perkin Elmer Pyris Diamond TG/DTA. Samples of about $5 \mathrm{mg}$ were heated in air from $25^{\circ} \mathrm{C}$ to $900^{\circ} \mathrm{C}$, at a rate of $5^{\circ} \mathrm{C} \mathrm{min}{ }^{-1}$. Differential scanning calorimetry was applied using a Q100 Thermal Analysis instrument between $25^{\circ} \mathrm{C}$ and $200^{\circ} \mathrm{C}$ under inert atmosphere (nitrogen), at heating and cooling rates of $2^{\circ} \mathrm{C} \mathrm{min}{ }^{-1}$. DSC measurements were done placing the sample in an open vessel to reproduce the conditions of TGA. High-resolution X-ray powder diffraction (XRD) patterns were collected with a monochromatic $\mathrm{Cu} \mathrm{K}_{\alpha}(\lambda=1.5418 \AA$ ) radiation source (operated at $30 \mathrm{keV}$ and $35 \mathrm{~mA})$ and a vertically mounted INEL cylindrical position-sensitive detector (CPS120), used in the Debye-Scherrer geometry to enable simultaneous acquisition of the diffraction profile over a $2 \theta$ range between $4^{\circ}$ and $120^{\circ}$ (with an angular step of $\left.0.029^{\circ}(2 \theta)\right)$. For the XRD measurements, the powder was placed into a Lindemann capillary tube $(0.5 \mathrm{~mm}$ diameter). X-ray photoelectron spectroscopy (XPS) measurements were performed under ultra-high vacuum $\left(2 \times 10^{-9}\right.$ $\mathrm{mbr}$ ) and data were collected using an SSX-100 (Surface Science Instruments) instrument equipped with a monochromatic $\mathrm{Al} \mathrm{K}_{\alpha} \mathrm{X}$-ray source $(\mathrm{h} \nu=1486.6 \mathrm{eV})$. The energy resolution was set to $1.2 \mathrm{eV}$ in order to minimize data acquisition time and maximize the signal-to-noise ratio and the photoelectron take off angle was $37^{\circ}$ with respect to the surface normal in order to minimize data acquisition time and maximize the signal-to-noise ratio. All binding energies were referenced to the $\mathrm{C} 1 s$ core level photoemission line at $285.0 \mathrm{eV}^{61}$. Spectral analysis included a Shirley background subtraction and peak deconvolution with Gaussian-Lorentzian functions in a least-squares curve-fitting program (Winspec) developed at the Laboratoire Interdisciplinaire de Spectroscopie Electronique, Universitaires Notre-Dame de la Paix, Namur, Belgium. For the N1s line, we applied a linear background subtraction because the low peak intensity did not allow for Shirley background subtraction. The photoemission peak areas of each element used to calculate the amount of each species within the probed volume were normalized to the sensitivity factors of each element specific to the spectrometer. All the measurements were made on freshly prepared samples in order to assure the reproducibility of the data. Three different spots were measured on each sample to check for reproducibility.

Evaluation of the in vitro cytotoxic activity of $\mathrm{oxC}_{60}$ - Cell lines. To consistently evaluate the cytotoxicity of water-soluble ox $\mathrm{C}_{60}$ we used two cancer cell lines, mouse leiomyosarcoma (LMS) and human lung cancer (A549) as well as a normal cell line, normal human fetal lung fibroblasts (MRC-5). The latter was kindly provided by Dr. Evangelos Kolettas, Laboratory of Biology, School of Medicine, Faculty of Health Sciences, University of Ioannina, Greece. All different cell lines were cultured in Dulbecco's Modified Eagles Medium (DMEM) enriched with $10 \%$ fetal bovine serum (FBS), $100 \mathrm{IU} / \mathrm{mL}$ penicillin, $100 \mu \mathrm{g} \mathrm{mL}^{-1}$ streptomycin and $1.4 \mathrm{mM} \mathrm{L}$-Gloutamin, at $37^{\circ} \mathrm{C}$, with $5 \% \mathrm{CO}_{2}$. MTT assay: The ability of the oxidized fullerenes to inhibit the cell growth was expressed by the average $\mathrm{IC}_{50}$ value (oxC $\mathrm{C}_{60}$ concentration required for $50 \%$ inhibition of cell growth) and was analyzed using the MTT assay (3-(4,5-dimethylthiazol-2-yl)-2,5-diphenyltetrazolium bromide) ${ }^{62}$. Briefly, $3 \times 10^{3}$ for both LMS and A549 cells, as well as $5 \times 10^{3}$ MRC- 5 cells, were cultured overnight on 96-well plates and culture media containing different concentrations (ranging from 200 to $2000 \mu \mathrm{g} \mathrm{mL}^{-1}$ ) of oxC $\mathrm{C}_{60}$ were added. The oxC $\mathrm{C}_{60}$ was dissolved in sterilized water (solvent). The 96 -well plates with culture media containing different volumes of solvent, equal to volumes of solutions added to the test wells, were considered as control. After incubation for $48 \mathrm{~h}, 50 \mu \mathrm{L}$ of MTT were added in each well from a stock solution $\left(3 \mu \mathrm{g} \mathrm{mL}^{-1}\right)$, and incubated for additional $3 \mathrm{~h}$. The yielded purple formazans were re-suspended in $200 \mu \mathrm{L}$ of DMSO, using a multi-channel pipette. The solution was spectrophotometrically measured $(540 \mathrm{~nm}$, subtract background absorbance measured at $690 \mathrm{~nm}$ ) using a microplate spectrophotometer (Multiskan Spectrum, Thermo Fisher Scientific, Waltham, USA). All the experiments were performed at least in triplicate. $\mathrm{IC}_{50}$ values were determined by the curve of percentage of inhibition versus dose.

Further chemical functionalization of $\mathrm{oxC}_{60}$ with octadecylamine. $100 \mathrm{mg}$ of oxidized fullerenes, dissolved in $50 \mathrm{~mL}$ of distilled water, were mixed with a solution of $300 \mathrm{mg}$ of octadecylamine (ODA) in $16.5 \mathrm{~mL}$ of $\mathrm{EtOH}$ while the $\mathrm{pH}$ was set to 7 and the system was stirred for $24 \mathrm{~h}$. The product was collected by centrifugation, 


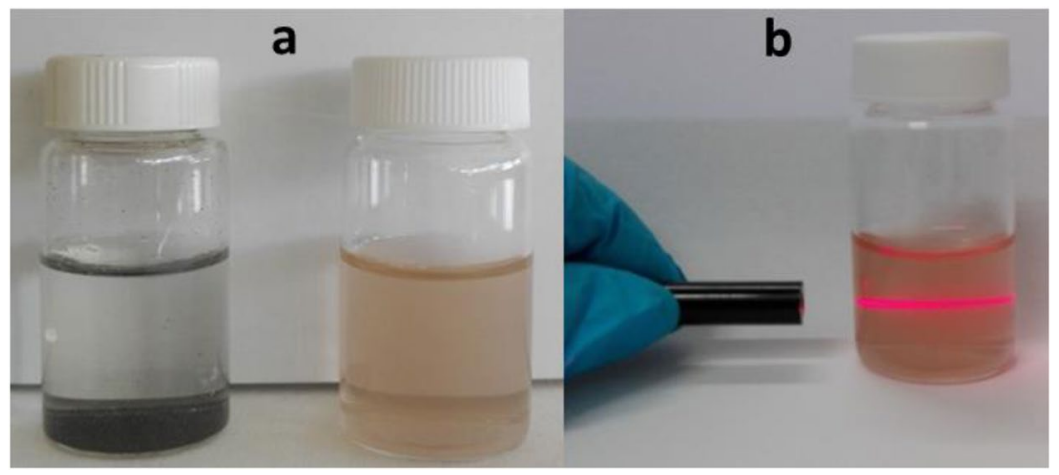

Figure 2. (a) Completely insoluble $\mathrm{C}_{60}$ molecules in water (left) and water soluble oxidized fullerene (right), (b) Tyndall scattering observed when a laser pointer is directed onto an aqueous colloidal dispersion of ox $\mathrm{C}_{60}$.

washed with ethanol and dried at room temperature (sample denoted as $\mathbf{o x C}_{\mathbf{6 0}}-\mathbf{O D A}$ ). The synthesized material presented a yield of approximately of $45 \%$ (based on the weighted mass).

Non covalent immobilization of laccase. Laccase from White rot fungi $(10,000 \mathrm{U} / \mathrm{mL}$, WrfL) was purchased from Creative Enzymes (New York, USA). Carbonyldiimidazole (CDI), N-hydrosuccinimidyl ester (NHS), Coomassie Brilliant Blue G-250 (CBB), Bromophenol Blue (BpB), 1-Hydroxybenzotriazole (HBT) and (4-(2-hydroxyethyl)-1-piperazineethanesulfonic acid) (HEPES) were purchased from Sigma. In our standard protocol, $3 \mathrm{mg}$ of oxC $_{60}-\mathrm{ODA}$ in $5 \mathrm{~mL}$ of acetate buffer $(0.1 \mathrm{M}, \mathrm{pH} 4.58)$ were sonicated for $30 \mathrm{~min}$. Then $1 \mathrm{~mL}$ of WrfL was added and the mixture was incubated under stirring for $1 \mathrm{~h}$ at $30^{\circ} \mathrm{C}$. The nanomaterial-enzyme conjugates were separated by centrifugation at $6,000 \mathrm{rpm}$ and then were washed three times with buffer solution to remove loosely bound protein. The immobilized WrfL was dried over silica gel and was stored at $4{ }^{\circ} \mathrm{C}$ until used.

Covalent immobilization of laccase via diimide-activated amidation. $\quad 3 \mathrm{mg}$ of oxC ${ }_{60}-\mathrm{ODA}$ in $6 \mathrm{~mL}$ of distilled water were sonicated for $30 \mathrm{~min}$. Then $1.2 \mathrm{~mL}$ of a $10 \mathrm{mg} \mathrm{mL}^{-1} \mathrm{CDI}$ aqueous solution was added to the above suspension. Under fast stirring, $2.3 \mathrm{~mL}$ of a $50 \mathrm{mg} \mathrm{mL}^{-1} \mathrm{NHS}$ aqueous solution were added quickly and the mixture was incubated for $30 \mathrm{~min}$ at $30^{\circ} \mathrm{C}$. The activated nanomaterials were separated by centrifugation at $6,000 \mathrm{rpm}$ and washed three times with HEPES buffer $(50 \mathrm{mM}, \mathrm{pH} 4.58)$ to remove the excess of CDI. The activated nanomaterials were re-dispersed in $5 \mathrm{~mL}$ of HEPES buffer solution. Then, $1 \mathrm{~mL}$ of WrfL was added and the mixture was treated as described for non-covalent procedure.

Dye decolorization. To study the decolorization ability of the immobilized enzymes, $0.1 \mathrm{mg} \mathrm{mL}^{-1}$ of immobilized laccase and $1 \mathrm{mM}$ HBT was added to each dye solution $(70 \mu \mathrm{M}$ of $\mathrm{CBB}$ and $\mathrm{BpB})$ followed by incubation in a rotary shaker $\left(30^{\circ} \mathrm{C}\right.$ and $\left.120 \mathrm{rpm}\right)$. The solution was sonicated for 3 minutes to achieve full and stable dispersion of the nanomaterial-enzyme conjugates. Samples were taken from each reaction mixture and the decrease in the absorbance at $545 \mathrm{~nm}$ was recorded in specific time intervals. The percentage of dye decolorization was calculated as the formula:

$$
\text { decolorization }(\%)=\left[\left(\mathrm{A}_{i}-\mathrm{A}_{t}\right) / \mathrm{A}_{i}\right] \times 100
$$

where, $\mathrm{A}_{i}$ : initial absorbance of the dye, $\mathrm{A}_{t}$ : absorbance of the dye at any time interval. Negative controls (reaction mixtures without enzyme) were designed as a reference to compare decolorization percent of treated samples. Each decolorization experiment was performed in triplicate and mean of decolorization percentage was reported.

\section{Results and Discussion}

The first indication of successful oxidation came from the solubility behavior of the products estimated at $13 \mathrm{mg} /$ $\mathrm{mL}$ (Fig. 2a), a high value compared to other synthetic procedures ${ }^{60}$ : The enhanced solubility in water and other polar solvents (like DMSO, $1 \mathrm{mg} / \mathrm{mL}$ ) can be explained only if a hydrophilic sheath of oxygen-containing groups attached to and surrounding the surface of the fullerene cage is present. Such a high dispersibility in water is expected for polar oxygen-containing groups, distributed more or less homogeneously around the spheroid thus preventing aggregation ${ }^{63}$. Tyndall scattering, observed when the beam of a laser pointer is directed onto an aqueous colloidal dispersion of $\mathrm{oxC}_{60}$, provides additional proof for the successful oxidation of fullerenes (as shown in Fig. 2b). This phenomenon is a clear evidence of an excellent dispersibility of $\mathrm{C}_{60}$ molecules in aqueous media.

Vibrational spectroscopy was employed to identify chemical and structural changes as well as to verify the molecular integrity of the $\mathrm{C}_{60}$ cage before and after the chemical modification. Figure 3 displays the Raman spectra of $\mathrm{C}_{60}$ and of oxC $\mathrm{C}_{60}$ powder samples. In pristine $\mathrm{C}_{60} 10$ of the 46 vibration modes are Raman active $\left(2 \mathrm{~A}_{\mathrm{g}}+8 \mathrm{H}_{\mathrm{g}}\right)$ and four $\left(4 \mathrm{~F}_{1 \mathrm{u}}\right)$ are infrared active $\mathrm{e}^{2,64,65}$. The most prominent bands centered at $499 \mathrm{~cm}^{-1}$ and $1471 \mathrm{~cm}^{-1}$ (Fig. 3a) are assigned to the symmetrical radial breathing motion of the sixty carbon atoms $\left(\mathrm{A}_{\mathrm{g}}(1)\right)$ and to the tangential stretching mode of five-fold pentagon carbons (pentagonal pinch mode $A_{g}(2)$ ), respectively ${ }^{2,64,65}$. The rest of the bands are attributed to the eight $\mathrm{H}_{\mathrm{g}}$ Raman active modes, distributed between $273 \mathrm{~cm}^{-1}$ and $1578 \mathrm{~cm}^{-1}$ as indicated in Fig. 3a. After oxidation, the number of active Raman modes decreases with respect to pristine fullerite (Fig. 3b). Only the most intense bands are visible after oxidation, and exhibit a small shift of approximately 


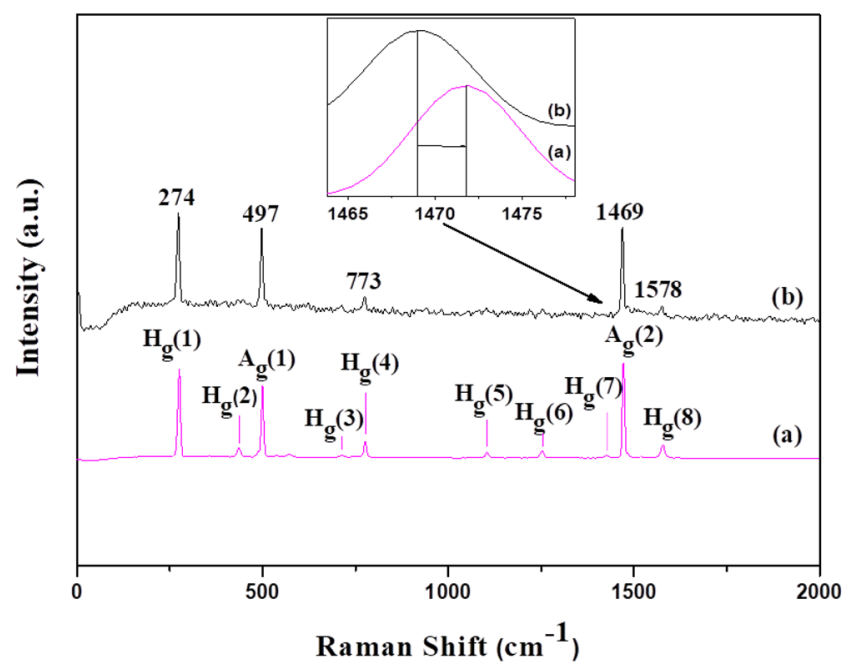

Figure 3. Raman spectra of (a) pristine $\mathrm{C}_{60}$ and (b) oxidized fullerene $\left(\mathrm{oxC}_{60}\right)$.

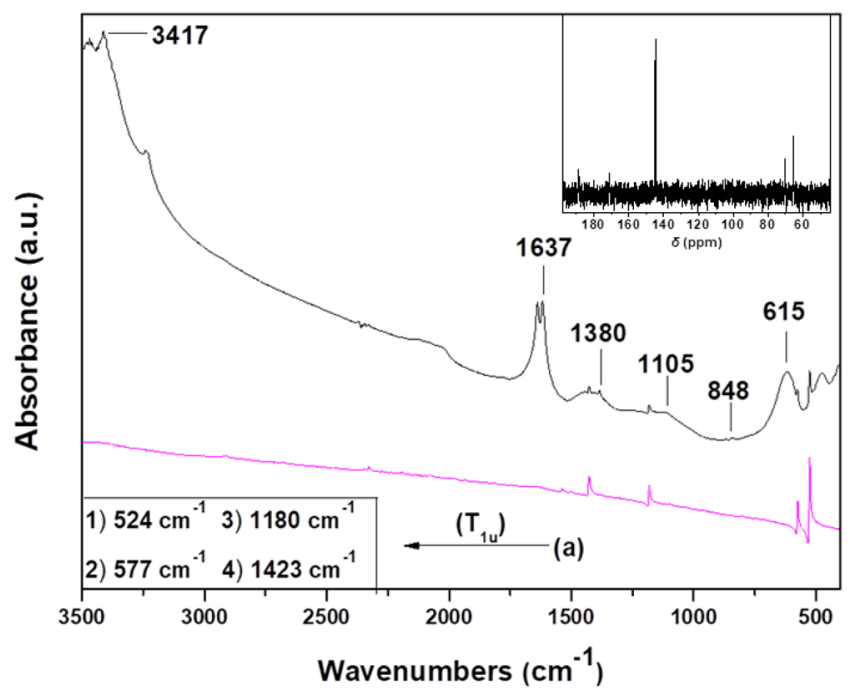

Figure 4. FT-IR spectra of $(\mathbf{a})$ pristine $\left(\mathrm{C}_{60}\right)$ and $(\mathbf{b})$ oxidized fullerene $\left(\right.$ oxC $\left._{60}\right)$. Inset: ${ }^{13} \mathrm{C}$ NMR spectrum of oxC 60 was recorded in $\mathrm{D}_{2} \mathrm{O}$.

$2 \mathrm{~cm}^{-1}$ with respect to those of $\mathrm{C}_{60}$. These changes can be attributed to hindrance of the free rotation motion due to the creation of oxygen-containing functional groups: while the $\mathrm{C}_{60}$ molecules in pristine fullerite behave as free rotors at room temperature, the addition of hydroxyl and epoxy/carbonyl groups on the surface of the cage likely leads to the reduction of this rotational movement at ambient temperature possibly due to steric effects or inter-molecular bonding ${ }^{66}$. Importantly, the $1469 \mathrm{~cm}^{-1}$ band persists after the oxidation process. This vibration is due to the symmetric $A_{g}$ vibration mode of the spherical framework of the $\mathrm{C}_{60}$ cage, thus confirming that the icosahedral structure is intact ${ }^{67,68}$.

The FTIR spectra of $\mathrm{C}_{60}$ and $\mathrm{oxC}_{60}$ are presented in Fig. 4. The four IR active vibration modes with $\mathrm{F}_{1 \mathrm{u}}$ symmetry of pristine fullerite (a) are located at wavenumbers of 524,577,1180, and $1423 \mathrm{~cm}^{-1}$ and assigned to radial displacements of the carbon atoms for the two lowest wavenumber bands and to tangential modes of carbon atoms for the two modes above $1000 \mathrm{~cm}^{-169}$. The infrared spectrum of the oxidized fullerene (b) reveals the existence of additional peaks compared to $\mathrm{C}_{60}$, namely bands at $615 \mathrm{~cm}^{-1}$ and $848 \mathrm{~cm}^{-1}$, which are assigned to wagging vibrations of hydroxyl groups and in the wavenumber range between $1050 \mathrm{~cm}^{-1}-1470 \mathrm{~cm}^{-1}$ three new bands, one centered at $1105 \mathrm{~cm}^{-1}$, which is attributed to stretching vibrations of $\mathrm{C}-\mathrm{O}-\mathrm{C}$ ether (epoxide) species ${ }^{70}$, and two located at $1380 \mathrm{~cm}^{-1}$ and $1442 \mathrm{~cm}^{-1}$ stemming from stretching vibrations of $\mathrm{C}-\mathrm{OH}$ groups $\mathrm{s}^{71}$. Finally, the intense band at $1637 \mathrm{~cm}^{-1}$ might be due to water bending, which would be in agreement with the increased hydrophilic character of the oxidized fullerene derivatives.

The successful oxidation of $\mathrm{C}_{60}$ was also assessed by ${ }^{13} \mathrm{C}$ NMR spectroscopy. Specifically, in the ${ }^{13} \mathrm{C}$ NMR spectrum of oxC $_{60}$ (Fig. 4 inset, right top), a peak at 144 ppm attributed to the carbon atoms of the cage is shown. Additionally, the peaks at 186 and $171 \mathrm{ppm}$ are assigned to carbon atoms of carbonyl and carboxyl groups, 


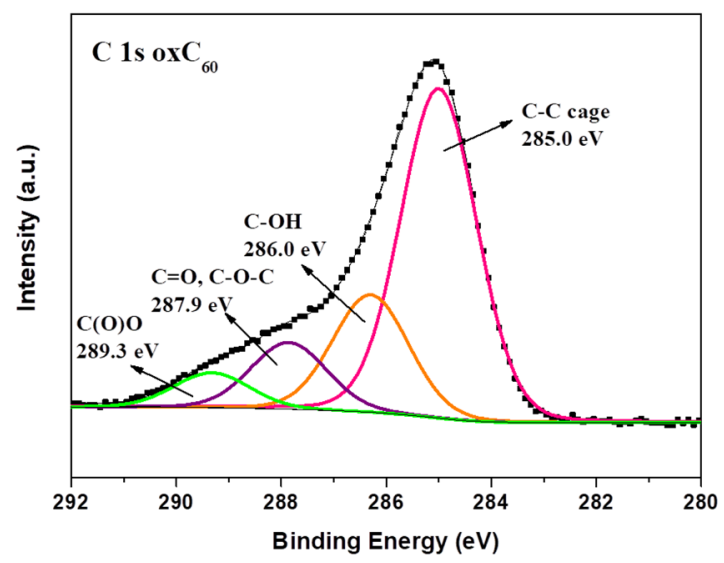

Figure 5. X-ray photoemission spectrum of the $\mathrm{C} 1 s$ core-level region of oxidized fullerene $\left(\mathrm{oxC}_{60}\right)$.

respectively, while the peaks at 71 and $67 \mathrm{ppm}$ are attributed to carbon atoms of epoxy and tertiary alcoholic moieties. Therefore, these findings, which are in line with the FTIR results and the literature ${ }^{72}$, suggest the successful decoration of oxC $_{60}$ with oxygen containing groups, which are mainly epoxy and hydroxyl groups, but also carbonyl and carboxyl moieties are present.

X-ray photoelectron spectroscopy (XPS) was applied to attest the presence of oxygen-containing functional groups covalently attached on $\mathrm{oxC}_{60}$. XPS is a widely used technique for the chemical characterization of fullerene derivatives since it is not only sensitive to all chemical elements (except $\mathrm{H}$ ), but also to the local environment surrounding the atoms of that element in a given compound. The C1s core level region of the XPS spectrum of oxC $_{60}$, presented in Fig. 5, displays four components at 285.0, 286.0, 287.9 and 289.3 eV. The most intense one at $285.0 \mathrm{eV}$ arises from the carbon-carbon aromatic bonds, and accounts for $60.1 \%$ of the total carbon intensity, while rest of the spectral intensity stems from carbon atoms that are involved in heterogeneous bonds. A percentage close to $60 \%$ may be expected since the maximum amount of side groups that can be covalently attach to single carbon atoms of the $\mathrm{C}_{60}$ cage without any two being adjacent, is 24 ; this is also the highest number stated for methylization, chlorination or bromination of fullerene ${ }^{3}$ entailing that 36 of the 60 atoms of the carbon cage (i.e., exactly $60 \%$ ) are not bonded to any functional group. The component centered at $286.0 \mathrm{eV}$ is due to carbon atoms forming $\mathrm{C}-\mathrm{OH}$ bonds and represents $21.6 \%$ of the total $\mathrm{C} 1 s$ intensity. The contribution at $287.9 \mathrm{eV}$ is assigned to $\mathrm{C}=\mathrm{O}$ double bonds and/or C-O-C epoxy moieties, and accounts for $12.1 \%$ of the total carbon signal. The spectral profile reveals a contribution located at $289.3 \mathrm{eV}$ which represents $6.2 \%$ of the total carbon amount. This weak contribution can be accounted for by considering that the strong oxidation treatment probably leads to the creation of a small amount of carboxyl groups. If this small percentage is discarded for the quantitative analysis, then our XPS results indicate that the average ox $\mathrm{C}_{60}$ molecule has 22 of the 60 carbon atoms involved in heterogeneous bonds and consists of $\mathrm{a}_{60}$ cage surrounded by 14 hydroxyl groups and by either 4 epoxy moieties or $4-m$ epoxy moieties and $2 m$ carbonyl oxygens with $m$ between 1 and 4 (the number of carbon atoms forming an epoxy moiety is twice the number of epoxy oxygens as each oxygen is linked to two carbons). This yields the average chemical formula for ox $\mathrm{C}_{60}$ as $\mathrm{C}_{60}(\mathrm{OH})_{14} \mathrm{O}_{\mathrm{n}}$ with $\mathrm{n}$ between 4 and 8 . Taking into account also the ratio between the intensities of the $\mathrm{C} 1 s$ and $\mathrm{O} 1 s$ photoemission lines (normalized with the respective sensitivity factors), these results confirm the successful oxidation of $\mathrm{C}_{60}$ by the creation of functional oxygen groups with a ratio of carbon to oxygen $(\mathrm{C} / \mathrm{O})$ equal to $2.2^{60}$.

Further evidence for successful oxidation of $\mathrm{C}_{60}$ is provided by thermal decomposition experiments: the required temperature for desorption of functional groups bound to $\mathrm{C}_{60}$ is significantly lower than the decomposition temperature of the pure fullerene, enabling also selective removal of the oxygen functional groups in a thermal scan (see below). Figure 6(a)presents the TGA plots of the oxC $_{60}$ sample and of the initial $\mathrm{C}_{60}$ material measured with a heating rate of $5^{\circ} \mathrm{C} / \mathrm{min}$ in air. As evident from the TGA curve of the pristine $\mathrm{C}_{60}$ sample, the combustion of fullerite takes place at temperatures between 500 and $700{ }^{\circ} \mathrm{C}$. In the case of oxidized fullerenes, the sample is found to combust at lower temperatures. In fact, the weight loss already starts before $100^{\circ} \mathrm{C}$ (due to loss of the epoxy and carbonyl side groups, see below) and progressively continues until a total weight loss is reached when heating the sample up to $700^{\circ} \mathrm{C}$. The main drop in the mass, corresponding to decomposition (combustion) of the oxidized fullerene cages, occurs between 350 and $470{ }^{\circ} \mathrm{C}$, i.e. at considerably lower temperature than the decomposition temperature of pure fulleren ${ }^{73}$ due to the presence of hydroxyl groups, as detailed in the following.

Figure 6(b) displays the scanning calorimetry data acquired on as-synthesized ox $\mathrm{C}_{60}$ during a heating-cooling cycle between 40 and $145^{\circ} \mathrm{C}$. Upon heating, the oxC $\mathrm{C}_{60}$ powder displays an irreversible double endothermic transition with onset at $65^{\circ} \mathrm{C}$, a more intense peak just above $80^{\circ} \mathrm{C}$ and a minor one above $100^{\circ} \mathrm{C}$. A very similar line shape is obtained by differentiating the TGA data (not shown). As visible in Fig. 6(a), such a double endothermic transition is accompanied by a mass loss of approximately $6.5 \%$, a value consistent with the loss of only the oxygen groups (epoxy and carbonyl) according to the chemical formula $\mathrm{C}_{60}(\mathrm{OH})_{14} \mathrm{O}_{\mathrm{n}}$ with $\mathrm{n}$ between 4 and 5 .

The confirmation that the endothermal mass loss is due to selective breaking of the oxygen side groups is provided by the analysis of the powder X-ray diffraction results. The room-temperature diffraction pattern of as synthesized $\mathrm{oxC}_{60}$ (Fig. 7) indicates that the sample is polycrystalline. The diffraction profile is quite different 

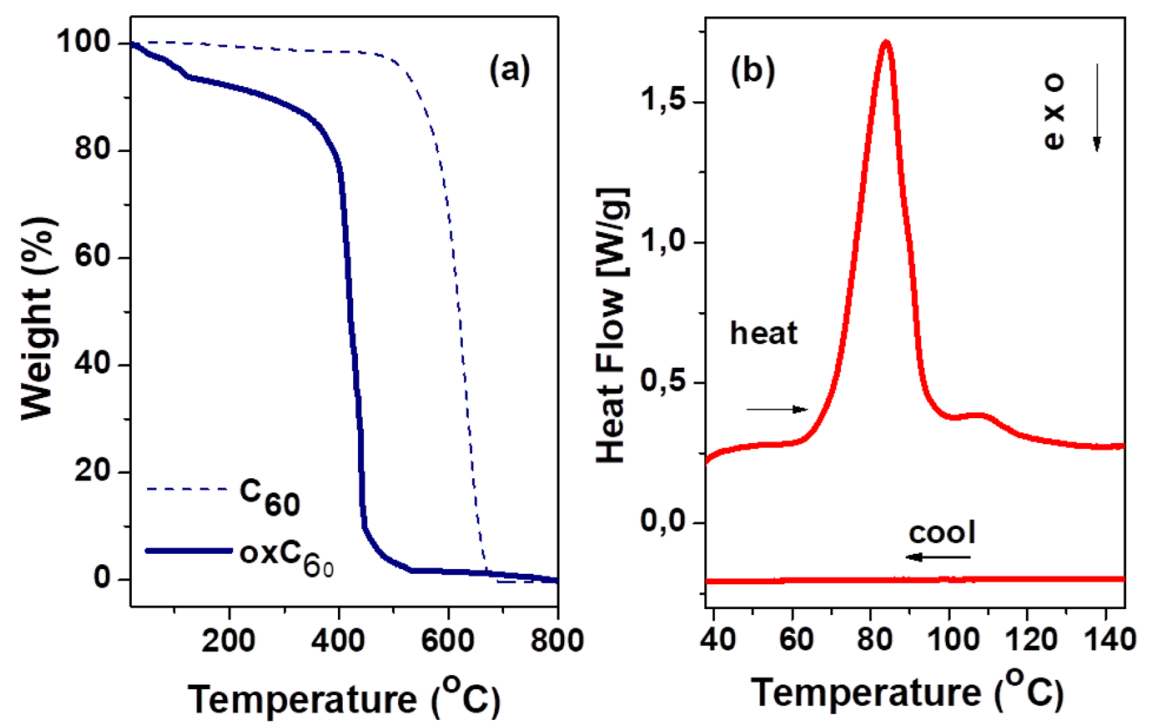

Figure 6. (a) TGA curves of pristine and oxidized fullerene. (b) DSC thermogram of oxidized fullerene between 40 and $145^{\circ} \mathrm{C}$ (heating-cooling cycle).

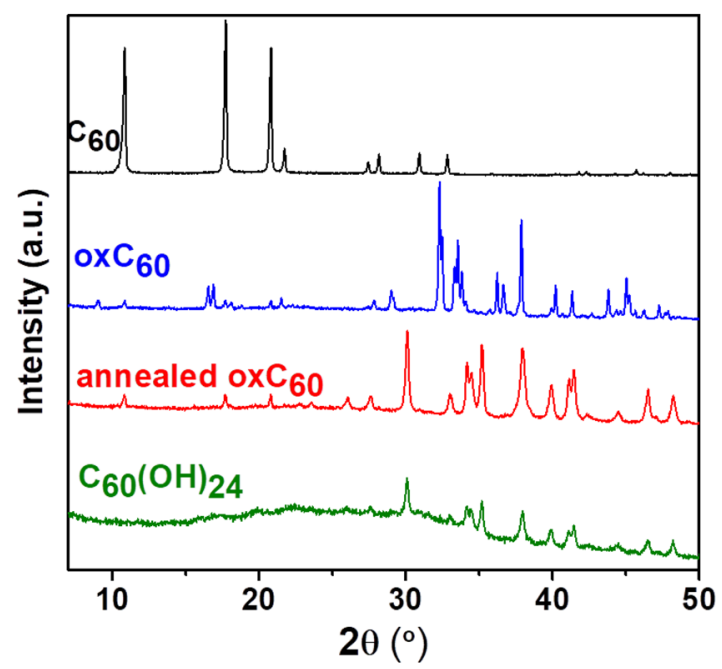

Figure 7. Room-temperature $\mathrm{X}$-ray powder diffraction pattern of oxidized fullerene $\left(\mathrm{oxC}_{60}\right)$, both prior to and after annealing at $100^{\circ} \mathrm{C}$. For comparison, also the $\mathrm{XRD}$ patterns of pristine fullerite $\left(\mathrm{C}_{60}\right)$ and of fullerol $\left[\mathrm{C}_{60}(\mathrm{OH})_{24}\right]$ are shown (own data).

from that of pristine fullerite (also shown in the same figure for comparison), which confirms the successful functionalization of $\mathrm{C}_{60}$ via oxidation ${ }^{74}$. Only traces amount of unreacted $\mathrm{C}_{60}$ are present, detectable by the presence of minor diffraction peaks in correspondence to the three main Bragg peaks of pristine fullerite. The pattern of $\mathrm{oxC}_{60}$ exhibits the first diffraction peak around $9^{\circ}$ in $2 \theta$ scale, i.e., at a significantly lower angle than the first peak of pristine $\mathrm{C}_{60}$ (approximately $11^{\circ}$ ), indicating that the lattice spacing is larger in $\mathrm{oxC}_{60}$ than in fullerite due to the presence of the side groups, which act as steric barriers against denser packing. Upon annealing at temperatures higher than $75^{\circ} \mathrm{C}$, the diffraction pattern of the oxidized fullerene powder changes abruptly, with the appearance of new peaks and the disappearance of all the peaks characteristic of the structure of as-synthesized ox $\mathrm{C}_{60}$ (at the same time, the pristine $\mathrm{C}_{60}$ peaks become more visible). The resulting spectrum (labeled as "annealed ox $\mathrm{C}_{60}$ " in Fig. 7) is strongly reminiscent of that of polyhydroxylated fullerenes (fullerol $\mathrm{C}_{60}(\mathrm{OH})_{24}$ ) or that of the related derivative $\mathrm{C}_{60}(\mathrm{ONa})_{24}{ }^{75}$, both of which were synthesized following a completely different route than that used here to produce $\mathrm{oxC}_{60}{ }^{53,76}$. The fact that the diffraction peaks of the $\mathrm{oxC}_{60}$ sample warmed to $80^{\circ} \mathrm{C}$ or above match those of fullerol indicates that annealing causes selective disruption of the oxygen adducts (epoxy and carbonyl), leading, as a result of the partial decomposition, to the formation of polyhydroxylated fullerenes. An only partial decomposition may be expected since the oxygen adducts are more reactive and therefore more labile than the hydroxyl groups, which in fullerol are lost only above $150{ }^{\circ} \mathrm{C}^{53}$. The partial decomposition and the survival of hydroxyl groups also rationalize why the final combustion of the sample occurs at much lower temperatures 


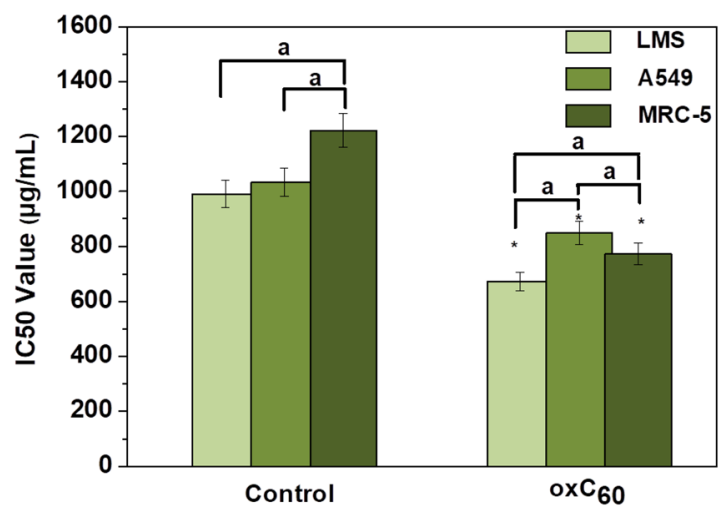

Figure 8. $\mathrm{IC}_{50}$ values in $\mu \mathrm{g} / \mathrm{mL}$ of oxC $_{60}$ on LMS, A549 and MRC- 5 cells. $* \mathrm{p}<0.05$, statistical significant difference compared to the control (solvent); ${ }^{\mathrm{a}} \mathrm{p}<0.05$, st $\mathrm{s}^{\mathrm{a}}$ tistical significant difference between the cell lines within the treatment group.

than for pristine $\mathrm{C}_{60}$ (Fig. 6(a)). The observation of a diffraction pattern identical to that of the high-symmetry $\mathrm{C}_{60}(\mathrm{OX})_{24}$ molecules $(X=\mathrm{H}, \mathrm{Na})$ is a direct confirmation that the quasi-spherical shape of pristine fullerene is retained after oxidation to $\mathrm{oxC}_{60}$. The synthesized product is therefore characterized by a symmetric distribution of functional moieties around the carbon skeleton ${ }^{63}$.

Very few studies have evaluated the cytotoxic activities of fullerenes. In the present study we evaluated the in vitro cytotoxic activity of oxC 60 against LMS and A549 (cancer cell lines) and MRC-5 (normal cell line). Figure 8 represents the $\mathrm{IC}_{50}$ values of the oxidized fullerenes $\left(\mathrm{oxC}_{60}\right)$ in all above mentioned cell lines. It was shown that the $\mathrm{oxC}_{60}$ presented high toxicity in all cell lines compared to the control (solvent) $(\mathrm{p}<0.05)$. Also, within the treatment group oxC 60 showed higher toxicity in LMS cells with an $\mathrm{IC}_{50}$ of $670 \pm 42 \mu \mathrm{g} / \mathrm{mL}$. Significant lower toxicity was shown in the other two cell lines with the $\mathrm{IC}_{50}$ values to be $850 \pm 20 \mu \mathrm{g} / \mathrm{mL}$ and $775 \pm 41 \mu \mathrm{g} / \mathrm{mL}$ for A549 and MRC-5, respectively $(\mathrm{p}<0.05)$.

It has been shown previously that $\mathrm{C}_{60}$ is able to inhibit the cell growth mainly due to its antioxidative properties $^{77}$ and partly through other mechanisms ${ }^{78,79}$. Also, fullerenes cause cytotoxicity in various cancer cell lines through the molecular events of oxidative stress ${ }^{80-82}$ or lipid peroxidation ${ }^{83,84}$ Here, we have shown that oxC $\mathrm{C}_{60}$ caused significant cytotoxicity in cancer and normal cell lines. Although the exact mechanism of action is not known, we speculate that ${ }^{\circ C_{60}}$ acts in the same way as fullerenes, and possibly through the oxidative stress mechanism.

To confirm the presence of epoxy moieties on the $\mathrm{oxC}_{60}$ cage and thus the possibility to further functionalize the oxidized fullerene, an additional experiment was performed in which a primary aliphatic amine (octadecylamine, ODA) was successfully attached through covalent bonding onto the surface of the oxC ${ }_{60}$ molecule. $^{2}$ Chemical grafting of the amine end groups via $\mathrm{SN}_{2}$ nucleophilic substitution reactions can only take place on the epoxy groups present in the oxidized fullerene. The organophilic character of the produced fullerene derivative resulted in an enhanced solubility in organic solvents including hexane $(0.4 \mathrm{mg} / \mathrm{mL})$, toluene $(1.5 \mathrm{mg} / \mathrm{mL})$, and chloroform $(1.5 \mathrm{mg} / \mathrm{mL})$, which provides the primary evidence for the covalent functionalization of oxC ${ }_{60}$ with ODA.

XPS and FTIR were employed to verify the covalent bonding of ODA on the surface of oxC $_{60}$. After functionalization with ODA, XPS measurements revealed the presence of new components stemming from the formation of covalent carbon-nitrogen bonds at the epoxy sites. More specifically, the analysis of the C1s XPS spectrum of oxC $_{60}$-ODA (Fig. 9 left) allows singling out the characteristic component due to carbons involved in the fullerene cage as well the $\mathrm{C}-\mathrm{C}$ chain of the -ODA at $285.0 \mathrm{eV}$ contributing with $58.2 \%$ to the total $\mathrm{C} 1 s$ intensity. The relative spectral weight of the feature at $285.9 \mathrm{eV}$ is significantly larger than in the ox $\mathrm{C}_{60}$ case (Fig. 5), changing from $21.6 \%$ before to $37.9 \%$ after the functionalization. This change is due to the creation of covalent $\mathrm{C}-\mathrm{N}$ bonds linking the organic chains to the carbon cage structure, as the binding energies values for carbon atoms linked to amine or hydroxyl groups are very similar ${ }^{62}$. Lastly, a weak component centered at $287.3 \mathrm{eV}$ and representing $3.9 \%$ of the total C1s intensity is attributed to carbonyl moieties, since the contribution of the epoxy oxygens is absent due to the creation of the $\mathrm{C}-\mathrm{N}-\mathrm{C}$ bridges of the organo-modified fullerene derivative. Very intriguing and a clear evidence for the integrity of fullerene molecules, is the total absence of the spectral signature of carboxyl groups in the $\mathrm{C} 1 s$ spectrum of $\mathrm{oxC}_{60}$-ODA (Fig. 9, left panel), unlike for the oxidized fullerene (Fig. 5). Thus the carboxyl groups, which were created (during the acid treatment) due to the breakage of a very small amount of fullerene cages, are absent after organic functionalization. This implies that these formations did not take part in the reaction as soon as carboxylic groups can react with amines under specific conditions and not in ambient conditions by which the experiment took place. A possible explanation for this is that the tiny amount of fullerenes possessing carboxylic moieties keep their hydrophilic character, and are thus removed from the reaction products upon washing with ethanol and water during the synthetic procedure. This provides a means to purify the oxC $_{60}$-ODA derivative.

Additional information on the type of interaction of ODA with the oxidized fullerenes comes from the N1s core level region of the photoelectron spectrum (Fig. 9, right-hand panel). The N1s line can be modeled with two main components centered at $399.2 \mathrm{eV}$ and $401.3 \mathrm{eV}$ binding energy, which correspond to the creation of the 

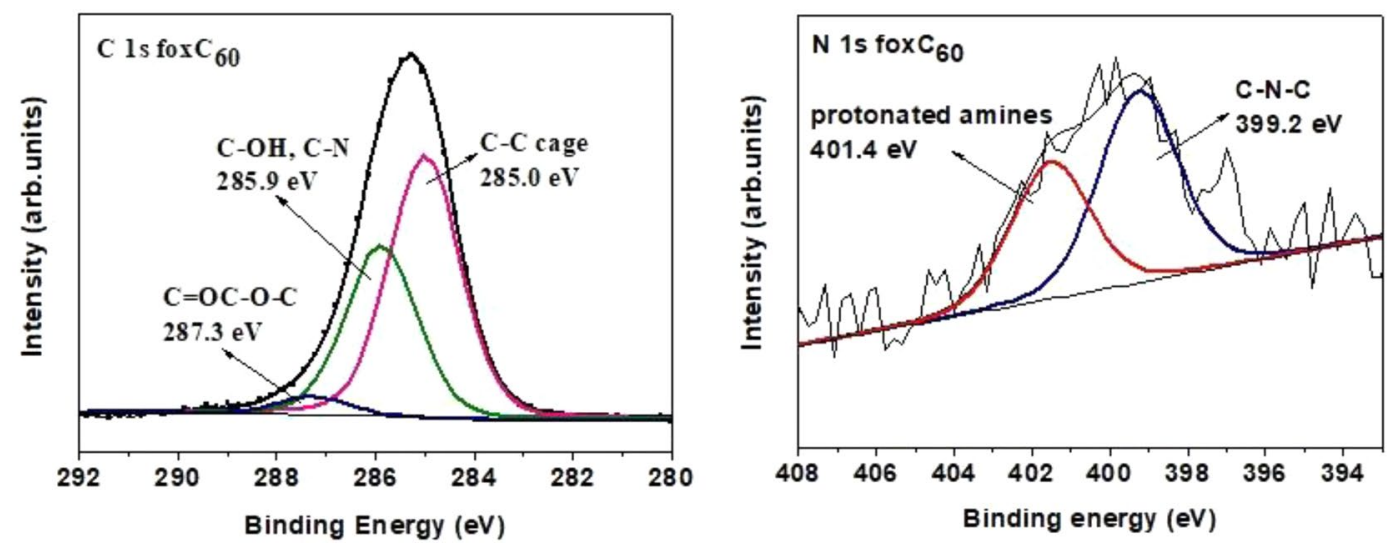

Figure 9. X-ray photoemission spectrum of the $\mathrm{C} 1 s$ (left) and $\mathrm{N} 1 s$ (right) core level regions of functionalized oxidized fullerene ( $\left.\mathrm{oxC}_{60}-\mathrm{ODA}\right)$.

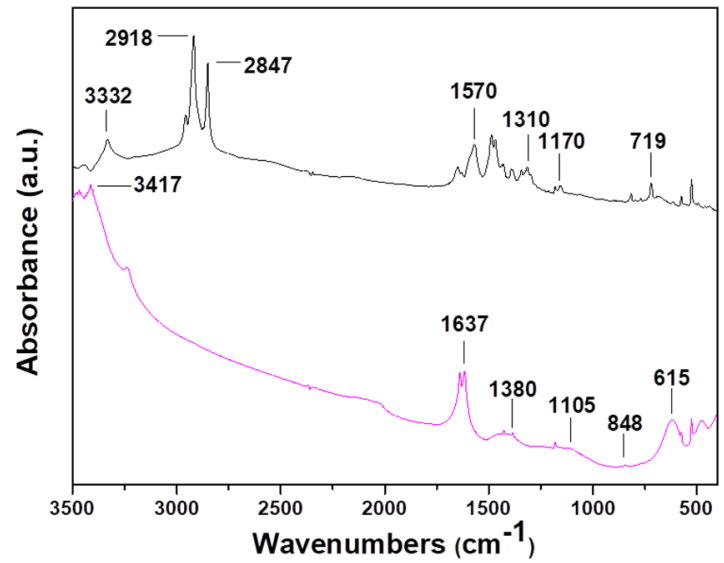

Figure 10. FTIR spectrum of oxidized $\mathrm{C}_{60}\left(\right.$ oxC $\left._{60}\right)$ (black line) and functionalized oxidized $\mathrm{C}_{60}\left(\right.$ oxC $_{60}$-ODA) (purple line).

epoxy amine bond $(\mathrm{C}-\mathrm{N}-\mathrm{C})^{85-87}$ and to protonated amines of the ODA moieties, respectively ${ }^{88}$. This entails that some of the ODA moieties are not covalently bonded to the fullerene cage, but are instead weakly bound to the sample (possibly via the formation of hydrogen bonds with the oxygen-containing groups of oxC $\mathrm{C}_{60}$ ). The carbon to nitrogen ratio is estimated at 20.2 showing that each oxidized fullerene molecule is surrounded by several (more than a dozen) ODA moieties. The carboxylated carbon formations, which are created (during the acid treatment) due to the breakage of a very small amount of fullerene cages is absent after the organic functionalization. For this reason by the organic functionalization of ox- $\mathrm{C}_{60}$ we can impart new properties to the hydrophilic fullerenes, which is very important for specific applications as well clear the rest of the carbon impurities, which are created from the strong oxidation and destroy the ball-shape of the $\mathrm{C}_{60}$.

The successful incorporation of ODA and the creation of a new fullerene derivative were further confirmed by FT-IR spectroscopy, as shown in Fig. 10. The spectrum of oxC ${ }_{60}-\mathrm{ODA}$ shows absorption bands, which are absent in the spectrum of pristine $\mathrm{C}_{60}$ (compare with Fig. 4). More specifically, for the functionalized fullerene we observe a band at $718 \mathrm{~cm}^{-1}$, which is attributed to the wagging vibration of $\mathrm{N}-\mathrm{H}$ stemming from non-covalently bonded ODA. The absorption bands at $1570 \mathrm{~cm}^{-1}$ (in plane-deformation) and $3332 \mathrm{~cm}^{-1}$ (stretching) are similarly assigned to vibrations of $\mathrm{NH}_{2}$ groups, while C-N stretching vibrations are observed at $1170 \mathrm{~cm}^{-1}$ and $1310 \mathrm{~cm}^{-1}$. Moreover, the peak at $1105 \mathrm{~cm}^{-1}$ due to epoxide vibrations disappears upon functionalization, indicating that the primary amines of ODA have reacted with the epoxide groups of the ox $\mathrm{C}_{60}$. These results together confirm the initial presence of epoxy oxygens in $\mathrm{oxC}_{60}$. Finally, the bands at 2847 and $2918 \mathrm{~cm}^{-1}$ are attributed to symmetric and asymmetric vibrations of $-\mathrm{CH}_{2}$-and $-\mathrm{CH}_{3}$ (alkyl groups), respectively, indicative of the presence of aliphatic hydrocarbon chains of ODA moieties attached to the carbon cage ${ }^{89}$.

Dye decolorization. The synthesized nanomaterial oxC60-ODA was used as matrix for the covalent and non-covalent immobilization of laccase from White rot fungi (WrfL), and its further application for the decolorization of two synthetic dyes of industrial and biotechnological interest, Coomassie Brilliant Blue G-250 $(\mathrm{CBB})$ and Bromophenol Blue $(\mathrm{BpB})$. Laccases are known to be capable of catalyzing the oxidation of synthetic dyes and hold potential for applications in sensing and bioremediation of industrial effluents ${ }^{90,91}$. The mediator 

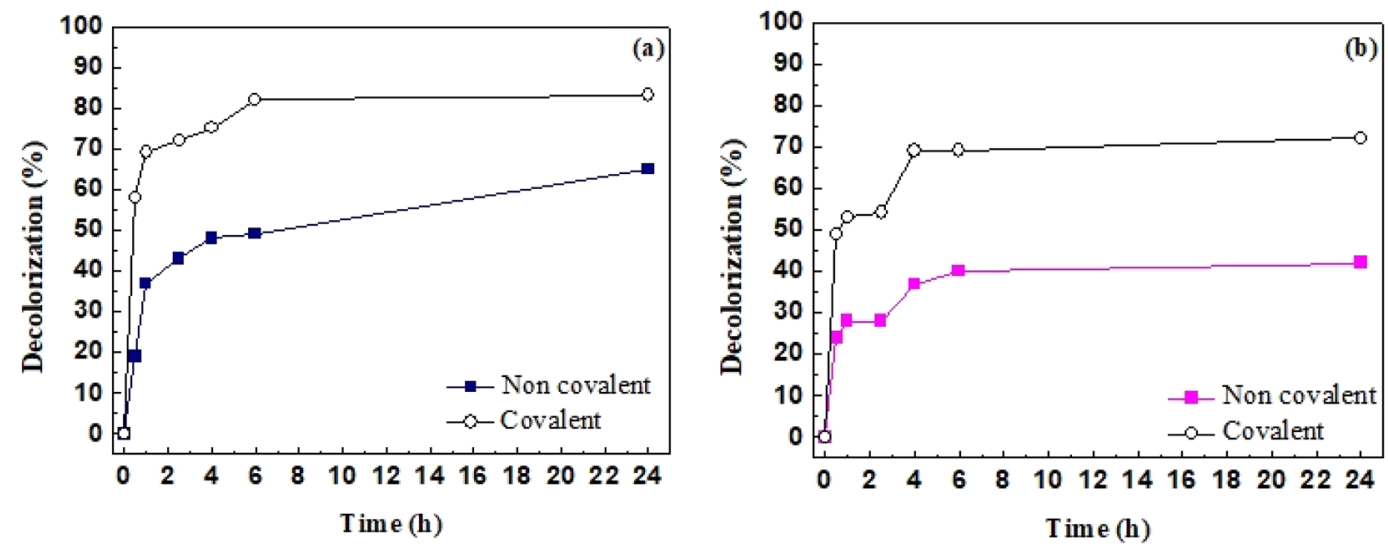

Figure 11. Decolorization of (a) $\mathrm{CBB}$ and (b) $\mathrm{BpB}$ by immobilized WrfL on oxC $\mathrm{C}_{60}-\mathrm{ODA}$ (In all cases, the standard deviation was $<3 \%)$.

hydroxybenzotriazole (HBT) was used to facilitate the decolorization of the chosen dyes. HBT acts as a sort of an electron bridge between the enzyme and the substrate. Firstly, HBT is oxidized by laccase, diffuses away from the enzymatic pocket and in a next step oxidizes other molecules, extending, this way, the range of substrates that can be efficiently catalyzed by laccase, and thus increasing its catalytic activity ${ }^{92}$. The decolorization efficiency of the immobilized laccase against $\mathrm{CBB}$ and $\mathrm{BpB}$ is presented in Fig. 11. As seen, in all cases studied, both covalent and non-covalent immobilized laccase appeared to efficiently decolorize the chosen dyes to a high extent. More specific, covalently immobilized WrfL presents high efficiency, since the decolorization rate for CBB and $\mathrm{BpB}$ reached up to 60 and $50 \%$, respectively, even after $0.5 \mathrm{~h}$ of incubation. The results indicate that this novel nanobiocalytic system shows great efficiency for dye degradation, even higher than other immobilized laccases reported previously ${ }^{93,94}$. The beneficial impact of different carbon-based nanostructures on the catalytic characteristics of enzymes has already been demonstrated ${ }^{92,95}$. The use of ODA for the functionalization of $\mathrm{oxC}_{60}$ and the targeted immobilization of WrfL increases the space between the nanomaterial and the protein, reducing in this way any undesired interactions between them ${ }^{95}$. Moreover, any substrate diffusion limitations are minimized, resulting in high catalytic activity for dye decolorization. The results indicate that $\mathrm{oxC}_{60}$-ODA can be excellent support for enzyme immobilization for use in applications of biotechnological and industrial interest.

\section{Conclusions}

A combination of characterization techniques was applied in order to illustrate the successful chemical oxidation of fullerene $\left(\mathrm{C}_{60}\right)$ into a highly oxidized analogue $\left(\right.$ ox $\left._{60}\right)$ by means of a variant of Staudenmaier's method, an easy oxidation protocol up to now extensively used for the chemical oxidation of graphite. This oxidation leads to the formation of a highly soluble fullerene derivative (that could be called "fullerene oxide" similar to graphene oxide) through the creation of oxygen-containing functional polar groups on the surface of $\mathrm{C}_{60}$, while retaining its spherical structure and represents a very crucial step for the utilization of the entire fullerene family in applications such as medicinal chemistry and biochemistry, which require solubility in various polar solvents. Apart from its simplicity, the main advantage of this method compared to others applied so far for the production of soluble $\mathrm{C}_{60}$ derivatives, arises from the creation of epoxy groups on the surface of the fullerene. A novelty of our synthetic approach is that it produces hydrophilic $\mathrm{C}_{60}$ molecules decorated with epoxy moieties in high yield but at low cost. The presence of these groups allows for further functionalization and thus for the creation of new hydrophilic fullerene derivatives without the need of high temperatures and complicated synthetic reactions. In fact, the epoxy groups can be readily modified via ring-opening reactions under various conditions. As representative example, a primary aliphatic amine (octadecylamine) was successfully attached through covalent bonding. The proposed method represents a novel simple, versatile and reproducible approach for the controllable production of various well-defined and stable fullerene derivatives by exploiting the well-established carbon chemistry.

Received: 12 December 2019; Accepted: 25 April 2020;

Published online: 19 May 2020

\section{References}

1. Kroto, H. W., Heath, J. R., Obrien, S. C., Curl, R. F. \& Smalley, R. E. C 60 Buckminsterfullerene. Nature 318, 162-163, https://doi. org/10.1038/318162a0 (1985).

2. Kratschmer, W., Lamb, L. D., Fostiropoulos, K. \& Huffman, D. R. Solid C 60 - A new form of carbon. Nature 347, 354-358, https://doi. org/10.1038/347354a0 (1990).

3. Taylor, R. \& Walton, D. R. M. The Chemistry Of Fullerenes. Nature 363, 685-693, https://doi.org/10.1038/363685a0 (1993).

4. Holczer, K. et al. Alkali-fulleride superconductors - synthesis, composition, and diamagnetic shielding. Science 252, 1154-1157 (1991).

5. Haddon, R. C. Electronic-structure, conductivity, and superconductivity of alkali-metal doped $\mathrm{C}_{60}$. Accounts of Chemical Research 25, 127-133, https://doi.org/10.1021/ar00015a005 (1992).

6. Rosseinsky, M. J. Fullerene intercalation chemistry. Journal of Materials Chemistry 5, 1497-1513, https://doi.org/10.1039/ jm9950501497 (1995). 
7. Allemand, P. M. et al. Organic molecular soft ferromagnetism in a fullerene $\mathrm{C}_{60}$. Science $\mathbf{2 5 3}$, 301-303, https://doi.org/10.1126/ science.253.5017.301 (1991).

8. Bendikov, M., Wudl, F. \& Perepichka, D. F. Tetrathiafulvalenes, oligoacenenes, and their buckminsterfullerene derivatives: The brick and mortar of organic electronics. Chemical Reviews 104, 4891-4945, https://doi.org/10.1021/cr030666m (2004).

9. Imahori, H. \& Fukuzumi, S. Porphyrin- and fullerene-based molecular photovoltaic devices. Advanced Functional Materials 14, 525-536, https://doi.org/10.1002/adfm.200305172 (2004).

10. Haddon, R. C. et al. $\mathrm{C}_{60}$ Thin-film transistors. Applied Physics Letters 67, 121-123, https://doi.org/10.1063/1.115503 (1995).

11. Anthopoulos, T. D. et al. High performance $\mathrm{n}$-channel organic field-effect transistors and ring oscillators based on $\mathrm{C}_{60}$ fullerene films. Applied Physics Letters 89 https://doi.org/10.1063/1.2387892 (2006).

12. Gan, L. B. et al. Fullerenes as a tert-butylperoxy radical trap, metal catalyzed reaction of tert-butyl hydroperoxide with fullerenes, and formation of the first fullerene mixed peroxides $\mathrm{C}_{60}(\mathrm{O})((\mathrm{OOBu})-\mathrm{Bu}-\mathrm{t})(4)$ and $\mathrm{C}_{70}((\mathrm{OOBu})-\mathrm{Bu}-\mathrm{t})(10)$. Journal of the American Chemical Society 124, 13384-13385, https://doi.org/10.1021/ja027714p (2002).

13. Bosi, S., Da Ros, T., Spalluto, G. \& Prato, M. Fullerene derivatives: an attractive tool for biological applications. European Journal of Medicinal Chemistry 38, 913-923, https://doi.org/10.1016/j.ejmech.2003.09.005 (2003).

14. Fortner, J. D. et al. $\mathrm{C}_{60}$ in water: Nanocrystal formation and microbial response. Environmental Science \& Technology 39, 4307-4316, https://doi.org/10.1021/es0498099n (2005).

15. Hirsch, A. Functionalization of single-walled carbon nanotubes. Angewandte Chemie-International Edition 41, 1853-1859, doi:10.1002/1521-3773(20020603)41:11<1853::aid-anie1853>3.0.co;2-n (2002).

16. Georgakilas, V. et al. Organic functionalization of carbon nanotubes. Journal of the American Chemical Society 124, 760-761, https:// doi.org/10.1021/ja016954m (2002).

17. Wilson, L. J. et al. Metallofullerene drug design. Coordination Chemistry Reviews 192, 199-207 (1999).

18. Da Ros, T. \& Prato, M. Medicinal chemistry with fullerenes and fullerene derivatives. Chemical Communications, 663-669 (1999).

19. Diederich, F. \& Thilgen, C. Covalent fullerene chemistry. Science 271, 317-323, https://doi.org/10.1126/science.271.5247.317 (1996).

20. Kräutler, B. The Chemistry of the Fullerenes. Von A. Hirsch. Thieme, Stuttgart, 1994. 203 S., Broschur 80.00 DM. - ISBN 3-13136801-2. Angewandte Chemie 107, 1654-1654, https://doi.org/10.1002/ange.19951071346 (1995).

21. Wilson, S. R. et al. In Fullerenes: Chemistry, Physics, and Technology (eds K. M. Kadish \& R. S. Ruoff) Ch. 3, 91-176 (John Wiley and Sons (2000).

22. Wilson, L. J. Medical applications of fullerenes and metallofullerenes. The Electrochemical Society Interface 8, 24-28 (1999).

23. Jensen, A. W., Wilson, S. R. \& Schuster, D. I. Biological applications of fullerenes. Bioorganic \& Medicinal Chemistry 4, 767-779, https://doi.org/10.1016/0968-0896(96)00081-8 (1996).

24. Nakamura, E. \& Isobe, H. Functionalized fullerenes in water. The first 10 years of their chemistry, biology, and nanoscience. Accounts of Chemical Research 36, 807-815, https://doi.org/10.1021/ar030027y (2003).

25. Hirsch, A. Addition Reactions of Buckminsterfullerene $\left(C_{60}\right)$. Synthesis 1995, 895-913, https://doi.org/10.1055/s-1995-4046 (1995).

26. Hirsch, A. The Chemistry of the Fullerenes: An Overview. Angewandte Chemie International Edition in English 32, 1138-1141, https://doi.org/10.1002/anie.199311381 (1993).

27. Hirsch, A. in Fullerenes and Related Structures Vol. 199 Topics in Current Chemistry (ed Andreas Hirsch) Ch. 1, 1-65 (Springer Berlin Heidelberg, (1999).

28. Maggini, M., Scorrano, G. \& Prato, M. Addition of azomethine ylides to $\mathrm{C}_{60}$ : synthesis, characterization, and functionalization of fullerene pyrrolidines. Journal of the American Chemical Society 115, 9798-9799, https://doi.org/10.1021/ja00074a056 (1993).

29. Prato, M. \& Maggini, M. Fulleropyrrolidines: A family of full-fledged fullerene derivatives. Accounts of Chemical Research 31, 519-526, https://doi.org/10.1021/ar970210p (1998).

30. Tat, F. T. et al. A new fullerene complexation ligand: N-pyridylfulleropyrrolidine. Journal of Organic Chemistry 69, 4602-4606, https://doi.org/10.1021/jo049671w (2004).

31. Friedman, S. H. et al. Inhibition of the hiv-1 protease by fullerene derivatives - model-building studies and experimental-verification. Journal of the American Chemical Society 115, 6506-6509, https://doi.org/10.1021/ja00068a005 (1993).

32. DaRos, T., Prato, M., Novello, F., Maggini, M. \& Banfi, E. Easy access to water-soluble fullerene derivatives via 1,3-dipolar cycloadditions of azomethine ylides to $\mathrm{C}_{60}$. Journal of Organic Chemistry 61, 9070-9072, https://doi.org/10.1021/jo961522t (1996).

33. Nakamura, E., Tokuyama, H., Yamago, S., Shiraki, T. \& Sugiura, Y. Biological activity of water-soluble fullerenes. Structural dependence of DNA cleavage, cytotoxicity, and enzyme inhibitory activities including HIV-protease inhibition. Bulletin of the Chemical Society of Japan 69, 2143-2151, https://doi.org/10.1246/bcsj.69.2143 (1996).

34. Wilson, S., Kadish, K. \& Ruoff, R. The Fullerene Handbook. Wiley New York, 437-465 (2000).

35. Castro, E., Garcia, A. H., Zavala, G. \& Echegoyen, L. Fullerenes in biology and medicine. Journal of Materials Chemistry B 5, 6523-6535, https://doi.org/10.1039/C7TB00855D (2017).

36. Illescas, B. M., Rojo, J., Delgado, R. \& Martín, N. Multivalent Glycosylated Nanostructures To Inhibit Ebola Virus Infection. Journal of the American Chemical Society 139, 6018-6025, https://doi.org/10.1021/jacs.7b01683 (2017).

37. Staudenmaier, L. Verfahren zur Darstellung der Graphitsäure. Berichte der deutschen chemischen Gesellschaft 31, 1481-1487, https:// doi.org/10.1002/cber.18980310237 (1898).

38. Chen, C.-H. et al. Effective Synthesis of Highly Oxidized Graphene Oxide That Enables Wafer-scale Nanopatterning: Preformed Acidic Oxidizing Medium Approach. Scientific Reports 7, 3908 (2017).

39. Diederich, F. et al. The Higher Fullerenes: Isolation and Characterization of $\mathrm{C}_{76}, \mathrm{C}_{84}, \mathrm{C}_{90}, \mathrm{C}_{94}$, and $\mathrm{C}_{70} \mathrm{O}$, an Oxide of D5h-C $\mathrm{C}_{70}$. Science 252, 548-551 (1991).

40. Wood, J. M. et al. Oxygen and methylene adducts of $\mathrm{C}_{60}$ and $\mathrm{C}_{70}$. Journal of the American Chemical Society 113, 5907-5908 (1991).

41. Kalsbeck, W. A. \& Thorp, H. H. Electrochemical reduction of fullerenes in the presence of $\mathrm{O}_{2}$ and $\mathrm{H}_{2} \mathrm{O}$ : Polyoxygen adducts and fragmentation of the $\mathrm{C}_{60}$ framework. Journal of Electroanalytical Chemistry and Interfacial Electrochemistry 314, 363-370 (1991).

42. Taylor, R. et al. Degradation of $\mathrm{C}_{60}$ by light. Nature 351, 277 (1991).

43. Creegan, K. M. et al. Synthesis and characterization of $\mathrm{C}_{60} \mathrm{O}$, the first fullerene epoxide. Journal of the American Chemical Society 114, 1103-1105 (1992).

44. Vassallo, A. M., Pang, L. S. K., Cole-Clarke, P. A. \& Wilson, M. A. Emission FTIR study of $\mathrm{C}_{60}$ thermal stability and oxidation. Journal of the American Chemical Society 113, 7820-7821 (1991).

45. Elemes, Y. et al. Reaction of $\mathrm{C}_{60}$ with Dimethyldioxirane-Formation of an Epoxide and a 1,3-Dioxolane Derivative. Angewandte Chemie International Edition in English 31, 351-353 (1992).

46. Weisman, R. B., Heymann, D. \& Bachilo, S. M. Synthesis and Characterization of the "Missing" Oxide of $\mathrm{C}_{60}$ : [5,6]-Open $\mathrm{C}_{60} \mathrm{O}$. Journal of the American Chemical Society 123, 9720-9721 (2001).

47. Hawkins, J. M. et al. Organic chemistry of $\mathrm{C}_{60}$ (buckminsterfullerene): chromatography and osmylation. The Journal of Organic Chemistry 55, 6250-6252 (1990).

48. Hawkins, J. M., Meyer, A., Lewis, T. A., Loren, S. \& Hollander, F. J. Crystal Structure of Osmylated $\mathrm{C}_{60}$ : Confirmation of the Soccer Ball Framework. Science 252, 312-313 (1991).

49. Hawkins, J. M., Loren, S., Meyer, A. \& Nunlist, R. 2D nuclear magnetic resonance analysis of osmylated $\mathrm{C}_{60}$. Journal of the American Chemical Society 113, 7770-7771 (1991).

50. Sommer, T. \& Roth, P. High-Temperature Oxidation of Fullerene $\mathrm{C}_{60}$ by Oxygen Atoms. The Journal of Physical Chemistry A 101, 6238-6242, https://doi.org/10.1021/jp971224f (1997). 
51. Dattani, R. et al. Fullerene oxidation and clustering in solution induced by light. Journal of Colloid and Interface Science 446, 24-30, https://doi.org/10.1016/j.jcis.2015.01.005 (2015).

52. Deng, J.-P., Mou, C.-Y. \& Han, C.-C. Oxidation of Fullerenes by Ozone. Fullerene Science and Technology 5, 1033-1044, https://doi. org/10.1080/15363839708013315(1997).

53. Macovez, R. et al. Ultraslow Dynamics of Water in Organic Molecular Solids. J. Phys. Chem. C 118, 4941-4950, https://doi. org/10.1021/jp4097138 (2014).

54. Tajima, Y., Takeshi, K., Shigemitsu, Y. \& Numata, Y. Chemistry of Fullerene Epoxides: Synthesis, Structure, and Nucleophilic Substitution-Addition Reactivity. Molecules 17, 6395 (2012).

55. Dreyer, D. R., Park, S., Bielawski, C. W. \& Ruoff, R. S. The chemistry of graphene oxide. Chem. Soc. Rev. 39, 228-240 (2010),

56. Enotiadis, A., Angjeli, K., Baldino, N., Nicotera, I. \& Gournis, D. Graphene-Based Nafion Nanocomposite Membranes: Enhanced Proton Transport and Water Retention by Novel Organo-functionalized Graphene Oxide Nanosheets. Small 8, 3338-3349, https:// doi.org/10.1002/smll.201200609 (2012).

57. Pavlidis, I. V., Patila, M., Bornscheuer, U. T., Gournis, D. \& Stamatis, H. Graphene-based nanobiocatalytic systems: recent advances and future prospects. Trends Biotechnol. 32, 312-320, https://doi.org/10.1016/j.tibtech.2014.04.004 (2014).

58. Kudanga, T., Nemadziva, B. \& Le Roes-Hill, M. Laccase catalysis for the synthesis of bioactive compounds. Applied Microbiology and Biotechnology 101, 13-33, https://doi.org/10.1007/s00253-016-7987-5 (2017).

59. Singh, R. L., Singh, P. K. \& Singh, R. P. Enzymatic decolorization and degradation of azo dyes - A review. International Biodeterioration \& Biodegradation 104, 21-31, https://doi.org/10.1016/j.ibiod.2015.04.027 (2015).

60. Vileno, B. et al. Spectroscopic and Photophysical Properties of a Highly Derivatized C60 Fullerol. Advanced Functional Materials 16, 120-128, https://doi.org/10.1002/adfm.200500425 (2006).

61. Lotya, M. et al. Liquid Phase Production of Graphene by Exfoliation of Graphite in Surfactant/Water Solutions. Journal of the American Chemical Society 131, 3611-3620, https://doi.org/10.1021/ja807449u (2009).

62. Spyrou, K. et al. Towards Novel Multifunctional Pillared Nanostructures: Effective Intercalation of Adamantylamine in Graphene Oxide and Smectite Clays. Advanced Functional Materials 24, 5841-5850, https://doi.org/10.1002/adfm.201400975 (2014).

63. Mitsari, E., Romanini, M., Zachariah, M. \& Macovez, R. Solid State Physicochemical Properties and Applications of Organic and Metallo-Organic Fullerene Derivatives. Curr. Org. Chem. 20, 645-661, https://doi.org/10.2174/1385272819666150730220449 (2016).

64. Kuzmany, H., Pfeiffer, R., Hulman, M. \& Kramberger, C. Raman spectroscopy of fullerenes and fullerene-nanotube composites. Philosophical Transactions of the Royal Society a-Mathematical Physical and Engineering Sciences 362, 2375-2406, https://doi. org/10.1098/rsta.2004.1446 (2004).

65. Bethune, D. S., Meijer, G., Tang, W. C. \& Rosen, H. J. The vibrational Raman spectra of purified solid films of $\mathrm{C}_{60}$ and $\mathrm{C}_{70}$. Chemical Physics Letters 174, 219-222, https://doi.org/10.1016/0009-2614(90)85335-A (1990).

66. Talyzin, A. New fullerene materials obtained in solution and by high pressure high temperature treatment $\mathrm{PhD}$ thesis thesis, Uppsala University (2001)

67. Birkett, P. R. et al. The Raman spectra of $\mathrm{C}_{60} \mathrm{Br}_{6} \mathrm{C}_{60} \mathrm{Br}_{8}$ and $\mathrm{C}_{60} \mathrm{Br}_{24}$. Chemical Physics Letters 205, 399-404, https://doi. org/10.1016/0009-2614(93)87141-O (1993).

68. Jing, D. \& Pan, Z. Molecular vibrational modes of $\mathrm{C}_{60}$ and $\mathrm{C}_{70}$ via finite element method. European. Journal of Mechanics - A/Solids 28, 948-954, https://doi.org/10.1016/j.euromechsol.2009.02.006 (2009).

69. Kroto, H. W., Allaf, A. W. \& Balm, S. P. C 60 - Buckminsterfullerene. Chemical Reviews 91, 1213-1235, https://doi.org/10.1021/ cr00006a005 (1991)

70. Fusco, C., Seraglia, R., Curci, R. \& Lucchini, V. Oxyfunctionalization of Non-Natural Targets by Dioxiranes. 3.1 Efficient Oxidation of Buckminsterfullerene $\mathrm{C}_{60}$ with Methyl(trifluoromethyl)dioxirane. The Journal of Organic Chemistry 64, 8363-8368, https://doi. org/10.1021/jo9913309 (1999).

71. He, H., Zheng, L., Jin, P. \& Yang, M. The structural stability of polyhydroxylated $\mathrm{C}_{60}(\mathrm{OH})_{24}$ : Density functional theory characterizations. Computational and Theoretical Chemistry 974, 16-20, https://doi.org/10.1016/j.comptc.2011.07.005 (2011).

72. Arrais, A. \& Diana, E. Highly Water Soluble $\mathrm{C}_{60}$ Derivatives: A New Synthesis. Fullerenes, Nanotubes and Carbon Nanostructures 11, 35-46, https://doi.org/10.1081/FST-120018667 (2003).

73. Spyrou, K. et al. A novel route towards high quality fullerene-pillared graphene. Carbon 61, 313-320, https://doi.org/10.1016/j. carbon.2013.05.010 (2013).

74. Ginzburg, B. M., Tuichiev, S., Tabarov, S. K., Shepelevskii, A. A. \& Shibaev, L. A. X-ray diffraction analysis of $\mathrm{C}_{60}$ fullerene powder and fullerene soot. Technical Physics 50, 1458-1461, https://doi.org/10.1134/1.2131953 (2005).

75. Zachariah, M. et al. Water-Triggered Conduction Mediated by Proton Exchange in a Hygroscopic Fulleride and Its Hydrate. J. Phys. Chem. C 119, 685-694, https://doi.org/10.1021/jp509072u (2015).

76. Macovez, R. et al. Hopping Conductivity and Polarization Effects in a Fullerene Derivative Salt. J. Phys. Chem. C 118, 12170-12175, https://doi.org/10.1021/jp503298e (2014).

77. Lu, L.-H., Lee, Y.-T., Chen, H.-W., Chiang, L. Y. \& Huang, H.-C. The possible mechanisms of the antiproliferative effect of fullerenol, polyhydroxylated $\mathrm{C}_{60}$, on vascular smooth muscle cells. British Journal of Pharmacology 123, 1097-1102, https://doi.org/10.1038/ sj.bjp.0701722 (1998).

78. Mastorakis, N. E., Kluev, V. V. \& Koruga, D. Advances in simulation, systems theory and systems engineering. 117-122 (WSEAS Press, 117-122) (2002).

79. Yang, X. L., Fan, C. H. \& Zhu, H. S. Photo-induced cytotoxicity of malonic acid $\left[\mathrm{C}_{60}\right]$ fullerene derivatives and its mechanism. Toxicology in Vitro 16, 41-46, https://doi.org/10.1016/S0887-2333(01)00102-3 (2002).

80. Gharbi, N. et al. [60]Fullerene is a Powerful Antioxidant in Vivo with No Acute or Subacute Toxicity. Nano Letters 5, 2578-2585, https://doi.org/10.1021/nl051866b (2005).

81. Bogdanović, G. et al. Modulating activity of fullerol $\mathrm{C}_{60}(\mathrm{OH})_{22}$ on doxorubicin-induced cytotoxicity. Toxicology in Vitro 18, 629-637, https://doi.org/10.1016/j.tiv.2004.02.010 (2004).

82. Isakovic, A. et al. Distinct Cytotoxic Mechanisms of Pristine versus Hydroxylated Fullerene. Toxicological Sciences 91, 173-183, https://doi.org/10.1093/toxsci/kfil27 (2006).

83. Sayes, C. M. et al. Nano- $\mathrm{C}_{60}$ cytotoxicity is due to lipid peroxidation. Biomaterials 26, 7587-7595, https://doi.org/10.1016/j. biomaterials.2005.05.027 (2005)

84. Tian, W.-d, Chen, K. \& Ma, Y.-q Interaction of fullerene chains and a lipid membrane via computer simulations. RSC Advances 4, 30215-30220, https://doi.org/10.1039/C4RA04593A (2014).

85. Ektessabi, A. M. \& Hakamata, S. XPS study of ion beam modified polyimide films. Thin Solid Films 377-378, 621-625 (2000).

86. Shin, J.-W., Jeun, J.-P. \& Kang, P.-H. Surface modification and characterization of N+ ion implantation on polyimide film. Macromolecular Research 18, 227-232, https://doi.org/10.1007/s13233-010-0310-x (2010)

87. Herrera-Alonso, M., Abdala, A. A., McAllister, M. J., Aksay, I. A. \& Prud'homme, R. K. Intercalation and stitching of graphite oxide with diaminoalkanes. Langmuir 23, 10644-10649, https://doi.org/10.1021/1a0633839 (2007).

88. Moses, P. R. et al. Chemically modified electrodes .9. X-ray photoelectron-spectroscopy of alkylamine-silanes bound to metal-oxide electrodes. Analytical Chemistry 50, 576-585, https://doi.org/10.1021/ac50026a010 (1978).

89. Dimos, K. et al. Naphthalene-based periodic nanoporous organosilicas: I. Synthesis and structural characterization. Microporous and Mesoporous Materials 158, 324-331, https://doi.org/10.1016/j.micromeso.2012.03.037 (2012). 
90. Legerská, B., Chmelová, D. \& Ondrejovič, M. In Nova Biotechnologica et Chimica 15, 90 (2016).

91. Upadhyay, P., Shrivastava, R. \& Agrawal, P. K. Bioprospecting and biotechnological applications of fungal laccase. 3 Biotech 6, 15, https://doi.org/10.1007/s13205-015-0316-3 (2016).

92. Patila, M., Kouloumpis, A., Gournis, D., Rudolf, P. \& Stamatis, H. Laccase-Functionalized Graphene Oxide Assemblies as Efficient Nanobiocatalysts for Oxidation Reactions. Sensors 16 (2016).

93. Teerapatsakul, C., Parra, R., Keshavarz, T. \& Chitradon, L. Repeated batch for dye degradation in an airlift bioreactor by laccase entrapped in copper alginate. International Biodeterioration \& Biodegradation 120, 52-57, https://doi.org/10.1016/j. ibiod.2017.02.001 (2017).

94. Phetsom, J., Khammuang, S., Suwannawong, P. \& Sarnthima, R. Copper-alginate encapsulation of crude laccase from Lentinus polychrous Lev. and their effectiveness in synthetic dyes decolorizations. Journal of Biological Sciences 9, 573-583 (2009).

95. Patila, M. et al. Graphene oxide derivatives with variable alkyl chain length and terminal functional groups as supports for stabilization of cytochrome c. International Journal of Biological Macromolecules 84, 227-235, https://doi.org/10.1016/j. ijbiomac.2015.12.023 (2016).

\section{Acknowledgements}

This work has been partially supported by the Spanish Ministry of Science and Innovation through project FIS2014-54734-P and by the Generalitat de Catalunya under project 2014 SGR-581. P.Z. and K.S. acknowledge the Ubbo Emmius Program for PhD fellowships. M.P. is very thankful to the IKY Foundation for the post-doc financial support (MIS 5001552).

\section{Author contributions}

P.Z., D.G., P.R. conceived the presented idea. P.Z., K.S., D.G. and P.R. wrote the manuscript with support from E.M., M.B., R.M., M.P., H.S., I.V., A.V. and A.E. The experiments for the synthesis of oxidized fullerenes and fullerene derivatives carried out by P.Z. The characterizations of the final nanomaterials performed from P.Z., K.S., E.M., M.B., Z.S. and R.M. The study of the cytotoxicity in vitro of oxidized fullerenes was performed by IV, A.V. and A.E. M.P. and H.S. accomplished the experiments for the biocatalysis applications.

\section{Competing interests}

The authors declare no competing interests.

\section{Additional information}

Correspondence and requests for materials should be addressed to P.Z., D.G. or P.R.

Reprints and permissions information is available at www.nature.com/reprints.

Publisher's note Springer Nature remains neutral with regard to jurisdictional claims in published maps and institutional affiliations.

(c) (i) Open Access This article is licensed under a Creative Commons Attribution 4.0 International License, which permits use, sharing, adaptation, distribution and reproduction in any medium or format, as long as you give appropriate credit to the original author(s) and the source, provide a link to the Creative Commons license, and indicate if changes were made. The images or other third party material in this article are included in the article's Creative Commons license, unless indicated otherwise in a credit line to the material. If material is not included in the article's Creative Commons license and your intended use is not permitted by statutory regulation or exceeds the permitted use, you will need to obtain permission directly from the copyright holder. To view a copy of this license, visit http://creativecommons.org/licenses/by/4.0/.

(c) The Author(s) 2020 